\title{
FATTY ACIDS COMPOSITION FROM ROSA CANINA AND PRUNUS SPINOSA PLANT FRUIT OIL
}

\author{
VANDA BĂBĂLĂU-FUSS ${ }^{a, b}$, LACRIMIOARA SENILA ${ }^{a}$, \\ ANCA BECZE ${ }^{\mathrm{a}}$, OANA BOGDANA AL-ZABEN ${ }^{\mathrm{b}}$, \\ MARCEL DIRJA $^{\mathrm{b}, *}$, MARIA TOFANĂ ${ }^{\mathrm{b}, *}$
}

\begin{abstract}
The objective of this study was to determine the fatty acids content from Rosa canina and Prunus spinosa plant fruit oil via ultrasoundassisted process. The extracted oil's fatty acids were converted into fatty acid methyl esters (FAME) before gas chromatography analyses (GC) equipped with flame ionization detection (FID). Results showed that Rosa canina oils contain mainly polyunsaturated fatty acids with the linoleic acid as the major fatty acids $(62.3 \%)$ followed by oleic acid $(28.6 \%)$, whereas Prunus spinosa oils contain $46.2 \%$ oleic acid and $32.6 \%$ linoleic acid. Rosa canina oil could be used as potential source of linoleic acid.
\end{abstract}

Keywords: Rosa canina, Prunus spinosa, Fatty acids, GC-FID

\section{INTRODUCTION}

In several Romanian regions, traditional uses of wild fruits have become an interesting issue. The data about the medicinal properties of certain plants are often lacking scientific base [1].

In the pharmaceutical market, about $40 \%$ of modern monomolecular drugs are derived directly or indirectly from plants [2]. Rosa canina and Prunus spinosa are among those plants that have been insufficiently explored in terms of scientific research related to human health, irrespective of the fact that it is highly rich in valuable bioactive compounds with protective and beneficial properties [3].

\footnotetext{
a INCDO-INOE2000, Research Institute for Analytical Instrumentation, ICIA Cluj-Napoca Subsidiary, 400293 Cluj-Napoca, Romania

b University of Agricultural Sciences and Veterinary Medicine Cluj-Napoca, Faculty of Food Science and Technology, 3-5 Calea Mănăştur Street, 400372, Cluj-Napoca, Romania

*Corresponding authors: maria.tofana@usamvcluj.ro; marcel.dirja@usamvcluj.ro
} 
Rosa canina, a member of the Rosaceae family, is a shrub widespread in Europe. Rose hip is a well-known herbal antiphlogistic which has been used in folk medicine for thousands of years due to its anti-inflammatory and pain-relieving properties [4]. Rosehips fruits are typically red to orange in color [5]. The fruits are comprised of $30-35 \%$ seeds and $65-70 \%$ pericarp. Rose hips are remarkable for their medicinal uses, which may be attributed to their profile of bioactive, especially antioxidant phenolics [6]. The seeds contain high amounts of polyunsaturated fatty acids. The fruits of Rosa canina contain high content of proanthocyanins and ascorbic acid (vitamin C) and can be used as regulator of blood fat caused by obesity, raised serum LDLcholesterol or physical stress [7]. Rosa canina fruits have long been used in food and nutrition due to their antioxidant potential, which is attributed to the presence of ascorbic acid and phenolics. A few studies have been reported on the chemical composition of rose hips essential oil [8]. Rose hips have anti-inflammatory properties because reduce inflammatory cytokines and chemokines, C-reactive protein and matrix metalloproteinases [9].

Plum species belong to genus Prunus, tribe Amygdaleae, subfamily Spiraeoideae of the large Rosaceae family. Blackthorn (Prunus spinosa) is the fruit of Prunus genus, in the Rosaceae family [10]. This species is growing in forest margins and open woodlands as part of Mediterranean thermophilus plant communities [11]. The fruits are popularly called "blackthorn" or "sloes" and despite their succulent appearance are far too bitter for human consumption, except as flavoring in home-made liqueurs. Sloes are bluish black, bloomy, globular drupe, 10-15 $\mathrm{mm}$ with green astringent flesh [12]. Prunus spinosa is usually $2-3 \mathrm{~m}$ tall deciduous shrub with long and sharp thorns. It has plum-like fruits that ripen late. Medicinal usage indicates vasoprotective, anti-inflammatory, diuretic, detoxifying (blood purifying), and spasmolytic activities of the flowers, and document their use as ingredients of herbal prescriptions [13].

Prunus spinosa and Rosa canina plants are insufficient explored regarding extraction of lipids and acid composition of extracted lipids.

The oil contains fatty acids (FAs) classified, according to the presence or absence of double bonds, in: saturated fatty acids (SFAs-without double bonds), monounsaturated fatty acids (MUFAs—-with one double bond) and polyunsaturated fatty acids (PUFAs - with two or up to six double bonds) [14]. The consumption of SFA must to be less that $10 \%$ of total energy intake due to its implications in cholesterol metabolism, according to World Health Organization [15]. The methods used for extraction of oil from different sources are liquid-liquid extraction, microwave assisted extraction, ultrasound assisted extraction, etc. The ultrasound assisted extraction is rapid, has high selectivity and short time of extraction $[16,17]$. 
The present work aims to investigate fatty acids composition of oils extracted from rose hip (Rosa canina) and blackthorn plant fruit by ultrasoundassisted extraction. The assess of feasibility of this functional ingredient rich in polyunsaturated fatty acids for improving public health will be also evaluated.

\section{RESULTS AND DISCUSSION}

\section{Lipid extraction yield}

The lipids were extracted from rose hip and blackthorn plant fruit species in two stages: (1) ultrasound assisted extraction with hexane and (2) conversion of oil into FAMES by transesterification. The yield of extracted lipids from rosehip fruit samples was $31.6 \% \pm 5.6 \%$ and $28.6 \% \pm 4.1 \%$ for blackthorn, respectively.

Rosa canina and Prunus spinosa fruits can be used in food and nutrition due to high lipid content. Other previous studies have reported that the oil content in dog rose (Rosa canina L.) from Spain was $9.35 \%$ by using Soxhlet extraction with petroleum ether [18]. The quality of oil is affected by the methods of extraction applied. According to Tan et al. (2016), hexane is the best solvent used for extraction of high yield oil from different seed samples [19]. Our experimental results indicate also that the highest yield of oil was extracted from rosehip and blackthorn fruit varieties.

\section{Chemical composition of oil from studied fruits}

Some studies have reported the chemical composition of oil extracted from Rosa canina and Prunus spinosa plant fruit [20, 21].

In the present study, GC-FID analysis of oils extracted from fruits revealed the presence of SFA, MUFA and PUFA fatty acids. The standard FAMES mixtures contain SFA, MUFA and PUFA. Chromatogram of the FAME standard mixture is presented in Figure 1.

The peaks of isomers cis and trans of oleic acid (C18:1 (n-9)) and linoleic acid (C18:2 (n-6) overlap. Also, the peak of cis-11,14,17-eicosatrienoic acid (C20:3(n-6)) overlaps with henicosanoic acid (C21:0) and cis-4,7,10,13, 16, 19-docosahexanoic acid (DHA, C22:6(n-6)) and nervonic acid (C24:1(n-9)) coelute. The fatty acids identified in the compositions of the investigated extracts and separated as FAMES by GC method are revealed in Figure 2. 


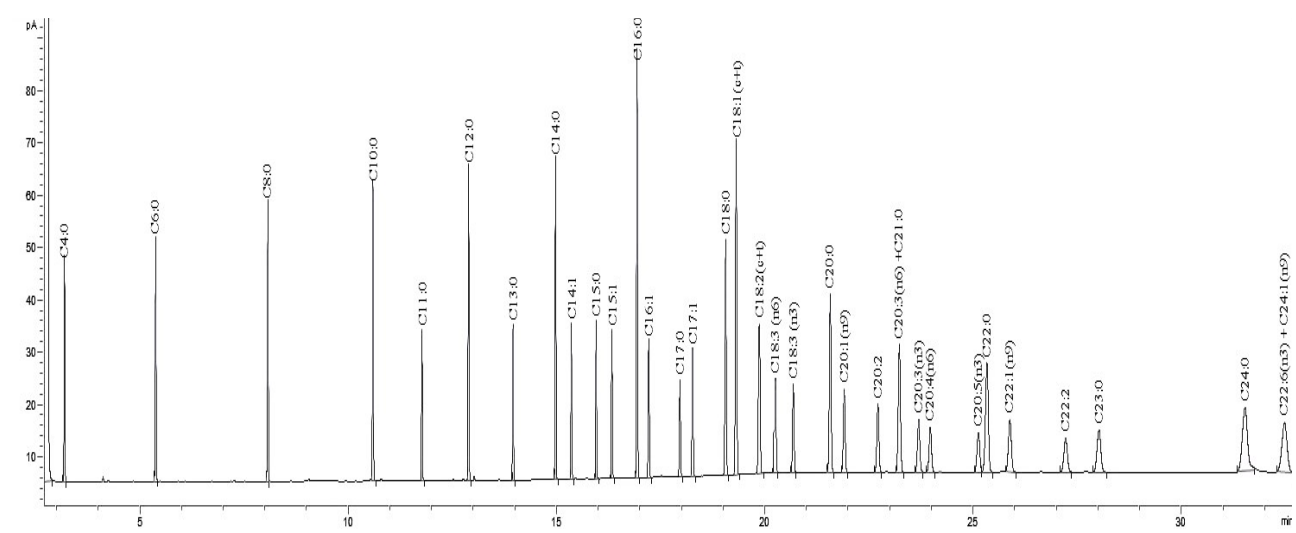

Figure 1. The GC chromatogram of FAMES standard mixture

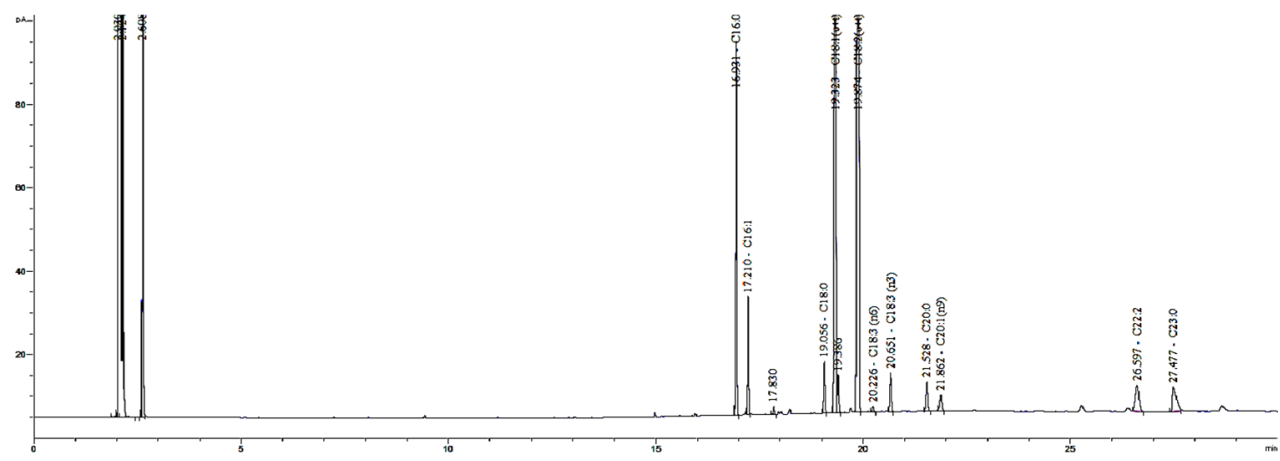

Figure 2. GC chromatogram of rose hip plant fruit oil

The SFAs acids found in studied oil samples are palmitic acid (C16:0), stearic acid (C18:0), arachidic acid (C20:0) and tricosanoic acid (C23:0). Palmitic acid (C16:0) was found to be $6.22 \pm 0.04 \%$ in rose hip oil, whereas in Prunus spinosa oil was $4.8 \pm 0.05 \%$. As can be seen in Table 1, three MUFA acids were found in both oils samples, like palmitoleic (C16:1), oleic acid (C18:1 (cisttrans)(n-9)) and gondoic acid (C20:1, n-9). The PUFA acids found in studied oils were linoleic (C18:2(cis+trans) (n-6), linolenic (C18:3, n-3), a-linolenic (C18:3, n-3), cis-13,16-docosadienoic acid (C22:2). The highest value of the linoleic acid (C18:2(cis+trans) (n-6) was obtained in rose hip oil $(62.3 \% \pm 0.80 \%)$, while in the blackthorn oil was found only 32.6 $\% \pm 0.40 \%$. Blackthorn oil contains $46.2 \% \pm 0.85 \%$ oleic acid (C18:1 (cis+trans)(n-9) as majority acid. Linolenic acid content in both varieties was below $1 \%$ of the total oil content. Natic et al. reported the following fatty acids compositions for blackthorn from Turkey: $43.9 \%$ oleic acid, $37.0 \%$ linoleic acid, $5.2 \%$ palmitic acid, $2.1 \%$ stearic acid and $2.1 \%$ arachidic acid [22]. 
Table 1. The content of SFA, MUFA and PUFA from extracted oil fruits

\begin{tabular}{|c|c|c|}
\hline Fatty acid & Rose hip oil (\%) & Blackthorn oil (\%) \\
\hline C16:0 & $6.22 \pm 0.04$ & $4.8 \pm 0.05$ \\
\hline C16:1(n-7) & $0.12 \pm 0.03$ & nd \\
\hline C17:0 & nd & $5.1 \pm 0.04$ \\
\hline C18:0 & $0.29 \pm 0.04$ & $0.05 \pm 0.01$ \\
\hline C18:1 (cis+trans) $(\mathrm{n}-9)$ & $28.6 \pm 0.90$ & $46.2 \pm 0.85$ \\
\hline C18:2(cis+trans) $(\mathrm{n}-6)$ & $62.3 \pm 0.80$ & $32.6 \pm 0.40$ \\
\hline C18:3 (n-6) & nd & nd \\
\hline C18:3(n-3) & $0.98 \pm 0.03$ & $0.86 \pm 0.04$ \\
\hline C20:0 & $0.5 \pm 0.02$ & $8.90 \pm 0.1$ \\
\hline $\mathrm{C} 20: 1(\mathrm{n}-9)$ & $0.1 \pm 0.02$ & nd \\
\hline C22:2 & $0.02 \pm 0.01$ & $1.08 \pm 0.06$ \\
\hline C23:0 & $0.03 \pm 0.01$ & $0.01 \pm 0.01$ \\
\hline$\Sigma S F A$ & $7.04 \pm 0.8$ & $18.86 \pm 0.6$ \\
\hline EMUFA & $28.82 \pm 0.88$ & $46.2 \pm 0.62$ \\
\hline EPUFA & $63.4 \pm 0.56$ & $34.54 \pm 0.95$ \\
\hline PUFAs/SFAs ratio & 9.0 & 1.83 \\
\hline
\end{tabular}

Values were reported in mean \pm standard deviations $(n=10)$. nd- not detected

The results obtained recommended the rose hip oil as a good source of linoleic acid. The obtained results for blackthorn oil varieties revealed a high content of oleic acid (C18:1 cis (n-9)) (46.2 \% 0.85\%). The important FAs for health are linolenic and linoleic acids. These FAs are known as essential PUFA since they cannot be synthesized by humans' body and must supplemented from food [23].

Omega- 6 has been found in high amount in rose hip oil $(62.3 \% \pm 0.80 \%)$ and $32.6 \% \pm 0.40 \%$ in blackthorn. A low quantity of omega-3 was detected in the studied samples (below 1\%). The oil obtained from blackthorn has a high content of arachidic acid (C20:0) $(8.90 \% \pm 0.1 \%)$. The consumption of oil obtained from blackthorn could prevent cholesterol gallstones by acting as a cholesterol solubilizer, but in reasonable quantities.

The PUFAs/SFAs ratio was very high in rose hip oil (9) and higher than 1 in blackthorn, which recommends their consumption for the prevention of cardiovascular diseases. The PUFA/SFA is an index used for determination of impact of human consumption of fatty acids and their effects on cardiovascular health, according to Chen et al [24]. The PUFA content is much higher in rose hip oil than in blackthorn oil. The dietary guidelines recommend the reduction of SFA intakes [25]. Due to high content of SFA, the oil obtained from blackthorn is recommended for consumption, but with some limitations.

In summary, rose hip oil proves to be a valuable source of linolenic acid and it is recommended for consumption for benefic health. 


\section{CONCLUSIONS}

In this paper, fatty acids composition of rose hip and blackthorn plant fruit oil were analyzed. The oils were extracted from fruits by ultrasound assisted method with hexane, and analyzed by gas chromatography. The main FA identified in rose hip oil $(62.3 \% \pm 0.80 \%)$ was linoleic acid. Total concentration of mono and polyunsaturated fatty acids in rose hip was $92.22 \%$ and $80.74 \%$ in blackthorn, respectively. The rose hip oil can be included in food industry due to high linoleic acid content. Due to high percent of SFA found in blackthorn, its limited consumption is recommended. The obtained results could be used for future applications in the field of cosmetics, phytopharmaceuticals and in the food industry.

\section{EXPERIMENTAL SECTION}

\section{Chemicals and Reagent}

The chemical such as isooctane, potassium hydroxide, methanol, sodium hydrogen sulphate monohydrate of analytic reagent grade, hexane, were purchased from Merck (Darmstadt, Germany). FAME standard mixture (Supelco 37 component FAME mix, CRM47885) was purchased from Sigma-Aldrich (Darmstadt, Germany). All solutions were prepared using ultrapure water (18.2 $\mathrm{M} \Omega / \mathrm{cm}, 20{ }^{\circ} \mathrm{C}$ ) obtained from a Direct-Q3 UV Water Purification System (Millipore, Molsheim, France).

\section{Sample Description}

Two different fruit samples (10 samples of each fruit type) were harvested from Cluj-Napoca region, Romania. All the samples were freeze-dried (FreeZone 2.5 LiterBenchtop freeze dry system, Labconco, Kansas, MO, USA) at $-40{ }^{\circ} \mathrm{C}$ and $-25 \mathrm{psi}$ for $24 \mathrm{~h}$ to uniform their moisture content. The freeze-dried samples were grounded using an agate mortar and pestle to obtain homogenized powders.

\section{Extraction of Lipids by Ultrasound Assisted Extraction}

An amount of $2 \mathrm{~g}$ of dried fruit sample was mixed with $10 \mathrm{ml}$ of $\mathrm{n}$-hexane and stirred for $500 \mathrm{rpm}$. The lipids were extracted in ultrasonic bath for $30 \mathrm{~min}$ at room temperature. After extraction, the lipids were separated by filtration, dried by $\mathrm{Na}_{2} \mathrm{SO}_{4}$ for water removal. The lipid content was determined gravimetrically by using an analytical balance, after hexane evaporation. 


\section{Preparation of Fatty Acid Methyl Esters (FAMEs)}

Fatty acids methyl esters analysis was performed using the method published by Petrović et al. [26] by conversion of the obtained acids from oils into FAMEs by transesterification with potassium hydroxide. The samples $(0.06 \mathrm{~g})$ were dissolved in isooctane, treated with $0.2 \mathrm{~mL}$ methanolic potassium hydroxide solution ( $2 \mathrm{~mol} / \mathrm{L})$ and vigorously stirred for $30 \mathrm{~s}$. Finally, the mixture was treated with $1 \mathrm{~g}$ sodium hydrogen sulphate to prevent the saponification of the methyl esters and to neutralize excess.

\section{GC Analysis and FAME quantification method}

The FAMEs content analysis was carried out using a GC-FID (Agilent Technologies, 6890N GC, Wilmington, DE, USA) equipped with a DB-WAX capillary column with polyethylene glycol stationary phase $(30 \mathrm{~m} \times 0.25 \mathrm{~mm}$ $\times 0.25 \mu \mathrm{m}$ ) and a flame ionization detector (Agilent 7683). The gases used for FID analysis were: hydrogen, $40 \mathrm{~mL} / \mathrm{min}$; air, $450 \mathrm{~mL} / \mathrm{min}$; and make-up helium, $30 \mathrm{~mL} / \mathrm{min}$.

The injection volume was $1 \mu \mathrm{L}$ in 1:20 split mode. The temperature program was as following: the initial oven temperature was set at $60^{\circ} \mathrm{C}$, held for $1 \mathrm{~min}$, from 60 to $200^{\circ} \mathrm{C}$ via a ramp of $10^{\circ} \mathrm{C} / \mathrm{min}$, held for $2 \mathrm{~min}$ and 200 to $220^{\circ} \mathrm{C}$ at a ramp of $5{ }^{\circ} \mathrm{C} / \mathrm{min}$, held for $20 \mathrm{~min}$ ). The temperature of the injector and detector was set to $250{ }^{\circ} \mathrm{C}$. The identification of FAs in samples was completed by comparing their retention times with those of the standard mixture. Reference standard of FAMEs (contain $2 \%-4 \%$ relative concentration) are dissolved in isooctane at a $0.01-0.1 \%(\mathrm{w} / \mathrm{v})$ to obtain a final concentration 0.2 or $0.4 \mathrm{mg} / \mathrm{mL}$ per FAME, before use.

\section{ACKNOWLEDGMENTS}

This research and APC was funded by the Competitiveness Operational Program of the Ministry of European Funds, contract no. 7/01.09.2016, code MY SMIS 105654.

\section{REFERENCES}

1. W. Guo, E. Kong, M. Meydani, Nutr. Cancer, 2009, 61, 807-810.

2. M. González-Tejero, M. Casares-Porcel, C.P. Sánchez-Rojas, J.M. RamiroGutiérrez, J. Molero-Mesa, A. Pieroni, J. Ethnopharmacol., 2008, 116, 341-357.

3. F. Demir, M. Ozcan, J. Food Eng., 2001, 47, 333-336.

4. M. Tabaszewska, D. Najgebauer-Lejko, NFS Journal, 2020, 21, 50-56. 
5. S. Kazaz, H. Baydar, S. Erbas, Czech J. Food Sci., 2009, 27(3), 178-184.

6. C. Chrubasik, B.D. Roufogalis, U. Muller-Ladner, S. Chrubasik, Phytother. Res., 2008, 22, 725-733.

7. S.A. Sargin, J. of Ethnopharmacol., 2021, 265, 113319.

8. K. Szentmihalyi, P. Vinkler, B. Lakatos, V. Illes, M. Then, Bioresour. Technol., 2002, 82, 195-201.

9. J. Gruenwald, R. Uebelhack, M.I. Moré, Phytomedicine, 2019, 60, 152958.

10. S. Calisir, M. Ozcan, H. Haciseferogullaro, D. Arslan, J. Food Eng, 2005, 66, 233-237.

11. V. Băbălău-Fuss, A. Becze, A. Moldovan, O.B. Greblă, A.I. Pop, I. Taloș, M. Tofană, Hop Med. Plants, 2020, 1-2, 218-227.

12. V. Băbălău-Fuss, A. Becze, M. Roman, A. Moldovan, O. Cadar, M. Tofană, Agriculture, 2020, 113, 110-115.

13. T. Murati, M. Miletić, A. Štefanko, I. Landeka Jurčević, I. Elez Garofulić, V. Dragović-Uzelac, I. Kmetič; S. Afr. J. Bot., 2019, 123, 36-42.

14. L. Senila, E. Neag, M.H. Kovacs, A. Becze, M. Senila, Appl. Sci., 2020, 10, 1589, 1-16.

15. WHO, 2009, Global Health Risks: Mortality and Burden of Diasease Attributable to Selected Major Risks, vol. 20, World Health Organization, Switzerland, Avenue Appia, 1211 Geneva 27.

16. H. Liu, Y. Yao, Y. Ma, X. Wang, Ultrason. Sonochem., 2020, 63, 104943.

17. N. Stevanato, C. da Silva, Ind. Crop Prod., 2019, 132, 283-291.

18. M. Armenteros; D. Morcuende, S. Ventanas, M. Estévez, J. Integr. Agric., 2013, 12(11), 1972-1981.

19. Z. Tan, Z. Yang, Y. Yi, H. Wang, W. Zhou, C. Wang, Appl. Biochem. Biotechnol., 2016, 179, 1325-1335.

20. N. Ahmad, F. Anwar, A.-H. Gilani, Rose Hip (Rose canina L.) Oils. Esential oils in Food Preservation, in Flavor and Safety, 2016, Chapter 76, 667-675.

21. S. Ouerghemmi, H. Sebei, L. Siracusa, G. Ruberto, A. Saija, F.K. Allouche, K. Dhaouadi, F. Cimino, M. Cristani, Phytochem. Anal., 2020, 31, 98-111.

22. M. Natić, D.D. Zagorac, I. Ćirić, M. Meland, B. Rabrenović, M.F. Akšić, Cold pressed oils from genus Prunus, in Cold Pressed Oils, 2020, Chapter 56, 637-658.

23. N. Kaur, V. Chugh, A.K. Gupta, J. Food Sci. Technol., 2014, 51(10), 2289-2303.

24. J. Chen, H. Liu, Mol. Sci., 2020, 21, 1-24.

25. S. Harrison, P. Couture, B. Lamarche, Nutrients, 2020, 12, 3232, 1-10.

26. M. Petrović, N. Kezić, V. Bolanća, Food Chem., 2010, 122, 285-291. 